University of Nebraska - Lincoln

DigitalCommons@University of Nebraska - Lincoln

Educational Psychology Papers and

Publications

Educational Psychology, Department of

June 2006

\title{
Effectiveness of a Computer-facilitated, Interactive Social Skills Training Program for Boys with Attention Deficit Hyperactivity Disorder
}

\author{
Kevin Fenstermacher \\ The Children's Center \\ Daniel Olympia \\ University of Utah \\ Susan M. Sheridan \\ University of Nebraska-Lincoln, ssheridan2@unl.edu
}

Follow this and additional works at: https://digitalcommons.unl.edu/edpsychpapers

Part of the Educational Psychology Commons

Fenstermacher, Kevin; Olympia, Daniel; and Sheridan, Susan M., "Effectiveness of a Computer-facilitated, Interactive Social Skills Training Program for Boys with Attention Deficit Hyperactivity Disorder" (2006). Educational Psychology Papers and Publications. 15.

https://digitalcommons.unl.edu/edpsychpapers/15

This Article is brought to you for free and open access by the Educational Psychology, Department of at DigitalCommons@University of Nebraska - Lincoln. It has been accepted for inclusion in Educational Psychology Papers and Publications by an authorized administrator of DigitalCommons@University of Nebraska - Lincoln. 
Published in School Psychology Quarterly 21:2 (2006), pp. 197-224. Copyright (C) 2006

American Psychological Association. Used by permission. "This article may not exactly replicate the final version published in the APA journal. It is not the copy of record."

http://www.apa.org/journals/spq/

\title{
Effectiveness of a Computer-facilitated, Interactive Social Skills Training Program for Boys with Attention Deficit Hyperactivity Disorder
}

\author{
Kevin Fenstermacher \\ The Children's Center \\ Daniel Olympia \\ University of Utah \\ Susan M. Sheridan \\ University of Nebraska-Lincoln
}

\begin{abstract}
Children with attention deficit hyperactivity disorder (ADHD) are at significant risk for a variety of comorbid conditions, including social skills deficits. Although interventions addressing various aspects of social difficulties with these children have been developed, few researchers have integrated new
\end{abstract}

The authors would like to acknowledge the numerous individuals who participated in the development and implementation of this project, The Children's Center and the University of Utah Psychoeducational Clinic for the use of its facilities, and the peer confederates and research participants for their time and effort throughout the study.

This article represents the results of a study awarded the Outstanding Dissertation of the Year Award for 2002 by Division 16 (School Psychology) of the American Psychological Association. Opinions expressed herein are those of the authors and do not reflect the opinions of the awarding agencies.

Address correspondence to the second author: Daniel Olympia, Department of Educational Psychology, 1705 Campus Center Drive, MBH 327, University of Utah, Salt Lake City, UT 84112; Email: olympia@ed.utah.edu. 
technology with existing social skills intervention literature and investigated such approaches empirically. The purpose of this study was to investigate the effectiveness of a computer-mediated social skills training program for children diagnosed with ADHD. The program presented specific social skill sequences to four children with ADHD in a variety of computer-facilitated formats with video peer modeling, social problem-solving, and reinforcement components. Participants' abilities to demonstrate specific social problem-solving skills effectively in a behavioral analogue environment were evaluated. The study used a multiple-probe variation of the multiple-baseline design (MBD) across participants. All participants demonstrated improvements in ability to demonstrate effective social problem-solving skills in analogue role-play assessments with live peers. Follow-up data at 3 and 6 week intervals indicated that participants maintained their gains over time.

Attention-deficit/hyperactivity disorder (ADHD) is a complex and chronic disorder affecting 3 to $5 \%$ of school-aged children (American Psychiatric Association, 1994). ADHD is believed to originate in early childhood (Barkley, Fischer, Newby, \& Breen, 1988), deemed to be chronic throughout childhood and adolescence (Klein \& Manuzza, 1991), and often associated with comorbid conditions such as oppositional-defiant disorder, learning disabilities, conduct disorder, academic underachievement, and social skills deficits (Barkley, 1998).

The social difficulties of children with ADHD are well established and clearly linked to key symptoms of the disorder (e.g., DuPaul, McGoey, Eckert, \& VanBrakle, 2001; Hoza, Owens, \& Pelham, 1999; Sheridan, 1998). Children with ADHD/I (predominantly inattentive) are more socially withdrawn (Edelbrock, Costello, \& Kessler, 1984), more likely to demonstrate deficits in sustaining attention (Barkley, 1990), and often display symptoms of anxiety and depression (Lahey, Schaughency, Hynd, Carlson, \& Nieves, 1987). Diagnostic features for $\mathrm{ADHD} / \mathrm{HI}$ (predominantly hyperactive/impulsive) and ADHD/COM (combined) subtypes include impulsivity, aggression, overactivity, noncompliance, and antisocial tendencies. Behaviors associated with either of these subtypes can directly or indirectly interfere with daily opportunities for prosocial interactions and, over time inhibit the development of meaningful relationships with others (Sheridan, 1995a) and lead to active social rejection experiences (Barkley, 1998). Additionally, children with ADHD frequently exhibit less positive social behaviors, initiate fewer positive peer interactions, experience lower rates of peer reinforcement, and demonstrate fewer cooperative social behaviors (Elliott \& Gresham, 1993). Indeed, the social performanceofchildrenwithADHDinkey areassuchassocialentry skills, problem-solving skills, and observance of participatory and conversational rules is 
regarded as highly problematic (DuPaul \& Stoner, 2003) and often precedes serious problems during adolescence and adulthood (Rubin, Bukowski, \& Parker, 1998).

\section{INTERVENTIONS FOR CHILDREN WITH ADHD}

Over the past two decades, it has been demonstrated that no single intervention for children with ADHD is effective, due to the myriad symptoms associated with the disorder (Muscott \& Guilford, 1994). In fact, the creation of a "prosthetic environment" using multiple interventions across multiple settings over longer time durations may be necessary for many children with the disorder (Barkley, 1998). While the singular impact of stimulant medication in treating symptoms of ADHD is strong (Greene \& Ablon, 2001), intervention is most effective when pharmacological treatment is paired with psychosocial, behavioral, and cognitive behavioral treatment strategies (Hoza, 2001; Pelham \& Gnagy, 1999). This may be particularly true for children with ADHD and social skills difficulties (Anastopoulos, DuPaul, \& Barkley, 1991; MTA Cooperative Group, 1999; Sheridan, Dee, Morgan, McCormick, \& Walker, 1996; Wells et al., 2000). Since the use of multimodal strategies represents the optimal treatment package when treating children with $A D H D$, the need for a wide range of adjunctive treatments to address symptom severity and the presence of specific behavioral difficulties, including social performance difficulties, across a range of settings and situations is apparent.

Consequently, the empirical validation of a variety of behavior or cognitive-behavior based treatment strategies to address social skill needs for students with ADHD is vital. A thorough review of research investigating the full range of these strategies is beyond the scope of this article. Interested readers are referred to Elliott, Gresham, and Heffer (1987); Sheridan and Walker (1999); and others. However, the limited empirical support for social skills interventions with this population has been a source of concern for many school psychologists, particularly when children with ADHD and social skills deficits are asked to demonstrate or generalize skills to other settings (DuPaul \& Stoner, 2003).

\section{APPROACHES TO SOCIAL SKILLS INTERVENTION}

Practitioners working with children having social skills deficits and ADHD have relied on a variety of cognitive behavioral and behavioral intervention techniques, including modeling, behavioral rehearsal, reinforced practice, peer coaching, and direct instruction (DuPaul \& Stoner, 2003). Often, these interventions are proscribed in a group for- 
mat, with students exhibiting similar characteristics meeting together with a psychologist for a specified duration of time.

\section{Group-facilitated Social Skills Training}

The interactive and performance aspects of social skills deficits and the fact that they regularly occur in a group context initially appeared well suited to group-facilitated approaches. However, recent evidence suggests that the current practice of grouping children for the purpose of teaching and practicing social skills may lead to unanticipated outcomes such as unintended changes in attitude toward antisocial behavior, identification with deviant peers, and assimilation of deviant values (Ang \& Hughes, 2002; Arnold \& Hughes, 1999; Dishion, McCord, \& Poulin, 1999). In fact, when peer aggregations in a group format are used to deliver interventions for at-risk youth, such practices ". . may make shopping for a deviant interpersonal environment much easier" (Arnold \& Hughes, 1999, p.110).

Group-facilitated social skills instruction has also served as an important aspect of strategies to promote generalization. The importance of generalizing newly acquired social skills has created interest in more comprehensive interventions that incorporate various levels of training (individual, group, class, school-wide), more systematic involvement of parents and teachers, homework assignments, and use of booster sessions and other enhancements to offset any negative effects of grouping these children and produce maximum gains across settings. Social skills interventions also frequently include a problemsolving component to promote generalization to other settings (Sheridan, 1995b). Some approaches have also attempted to teach and support specific social skills using imbedded instruction and positive behavior plans to teach and reinforce skills in naturally occurring contexts (Sheridan, Hungelmann, \& Maughn, 1999; Sugai \& Lewis, 1996). For example, the Tough Kid Social Skills Program (Sheridan, 1995a; Sheridan et al., 1996) provides such a comprehensive treatment modality. Initial results of group-based interventions, which included didactic training in conversation skills, problemsolving, and anger/impulse control strategies, have in fact produced impressive gains in the sessions themselves, but generalization to other settings and situations continues to be problematic (Gresham, 2002).

\section{Computer-mediated Social Skills Training}

Along with traditional strategies for social skills assessment and instruction, novel techniques are also emerging, including the use of computer technology and the integration of video and computer-based so- 
cial simulations with instructional content (Muscott \& Guilford, 1994; Smokowski, 2003). The potential advantages are numerous. Computer programs can present stimulus events using video content that maintains close fidelity with the actual phenomenon of social interaction. The content of these stimuli can be constructed to reflect actual social interactions (Irvin \& Walker, 1994), and a computer simulation can be suspended at any point and for any length of time to deliver relevant instruction during the practice activity (Kass, Burke, Blevis, \& Williamson, 1994). Computer-facilitated social skills intervention can also optimize available resources and more importantly, avoid potential negative effects of group treatment (Arnold \& Hughes, 1999; Dishion et al., 1999) through individual instruction.

Several studies provide initial support for the use of interactive video-based interventions to address social skills problems. For example, earlyworkbyWalker, Irvin, andothers describes foundational development, application, and evaluation of technology-supported assessment of social skills for children (Irvin \& Walker, 1994; Matthys, Cuperus, \& Van Engeland, 1999); and later studies by Margalit and others addressed the integration of computer-facilitated technology and social skills training for children with behavioral and learning disabilities (Margalit, 1995a), mild intellectual disabilities (Margalit, 1995b; Margalit \& Weisel, 1990) and children with ADHD (Carroll, Bain, \& Houghton, 1994). Empirical support for the use of technology-supported social skills interventions in a more interactive format was provided by Carroll et al. (1994) who investigated the use of video-based vignettes of classroom social behavior to improve attention and comprehension of social behaviors for children with attention disorders (ADHD). Vignettes of classroom-based social situations were shown to 72 children (aged 10-13) with ADHD followed by videotaped responses portraying positive (appropriate), neutral, and negative (inappropriate) behaviors from students. Findings indicated that students had higher levels of attention and comprehension when they could control their choice selection across potential responses and the presentation included positive (appropriate) and negative (inappropriate) models. Importantly, the purpose of this study focused primarily on the instructional effectiveness of the technology, not the impact of a specific curricula or generalized behavioral outcomes. These early empirical findings suggest strong promise for technology-supported applications to teach appropriate social skills to at-risk populations and to improve generalization of social skills from a training context to actual social situations.

While there is a counter-intuitive notion that social skills can be taught, practiced, and reinforced effectively in essentially a nonsocial context (i.e., interacting with a computer), the use of technology-sup- 
ported social skills instruction may be a viable, but as yet untested, adjunct and alternative to more traditional approaches. Issues regarding generalization of social skills acquired using these interventions to natural environments is a concern that has yet to be resolved completely (Holsbrink-Engels, 1997; Smokowski, 2003).

\section{PURPOSE OF THE PRESENT STUDY}

Given the short-and long-term negative consequences of poor social interaction skills for many children with ADHD, evidence-based interventions for social skills training are needed. Although traditional group-based interventions have demonstrated some success in improving children's social skills and appear to be a preferred intervention modality, caution is the rule when grouping children for social skill interventions. Given previous efforts and potential advantages associated with multimodal treatment strategies and technology-based interventions for children with $\mathrm{ADHD}$, the marriage of social skills training activities with an interactive, computer-facilitated training environment is a logical step in the evolution of social skills training.

Using an evidence-based social skills intervention linked to a computer-facilitated learning environment, the present study evaluated treatment effects of an interactive, computer/multimedia-based social skills training program developed for children with ADHD.

Effectiveness of the program was determined by the ability of children diagnosed with ADHD to (a) learn specific social problem-solving skills using an interactive (nonlinear), computer-facilitated training program, and (b) generalize the use of these skills to both virtual (video/computer-facilitated) and analogue (in vivo behavioral roleplay) environments. Outcomes were determined by the acquisition of social problem-solving skills knowledge demonstrated during behavioral analogue assessments (in vivo role plays) during treatment and at 3 and 6 weeks follow-up. Parent and participant ratings of treatment effectiveness and treatment acceptability were also used to address levels of consumer satisfaction.

\section{Participants}

\section{METHOD}

Participants were recruited from two local school districts and consisted of four males enrolled in Grades 4 through 7, ranging in age from 10 to 13. Three participants were Caucasian while one participant was biracial (African American/Caucasian). All participants had received support from a school psychologist during the previous year 
(e.g., consultation with teacher, behavior tracking, behavior support plans). Each participant met the following criteria: (a) a primary DSM III-R diagnosis of Attention-Deficit/Hyperactivity Disorder (ADHD) or a primary DSM-IV diagnosis of Attention-Deficit Disorder: Predominantly Hyperactive/Impulsive Type (ADD/HI) or Attention-Deficit Disorder: Combined Type (ADD/COM); (b) a standard (T) score of 67 or higher on the Conners' Parent Rating Scale (Conners, 1987); (c) a standard score of 85 or lower on the Social Skills Rating Scale: Parent and/or Teacher Form (Gresham \& Elliott, 1990); and (d) not currently participating in treatment specifically targeting the acquisition or generalization of social skills. Licensed psychologists or child psychiatrists at local clinics or mental health facilities evaluated all participants. Diagnostic methods used by these professionals included developmental histories, clinical interviews (parent and child), review of prior records (psychoeducational, educational, and mental health), and behavioral rating scales (e.g., Conners' Rating Scales, Child Behavior Checklist). Consistent with their diagnosis, each participant demonstrated less than a $50 \%$ mastery of targeted social problem-solving skills as assessed through direct observations during the initial analogue role-play scenarios. All children appeared to have average intelligence based on previous assessments, and no children with known cognitive delays were included. Initially, six participants were referred for participation in the study, but two students were disqualified for participation due to age and an inability to participate in all scheduled sessions. Participant 2 was the only student currently using stimulant medication to address symptoms of ADHD. A summary of participant characteristics is presented in Table 1.

The computer-facilitated, interactive social skills training and analogue role-play observations were completed at two clinic settings (one university-based psychoeducational clinic, and one private, nonprofit outpatient agency for young children and their families) in a large western U.S. city. All experimental procedures were conducted during the late spring and summer months, when school was not in session. Two sites were used to facilitate ease of access for participants. Each location was similar in terms of physical facilities. The same computer and headphones were used at each location. Each room was equipped with a one-way observational mirror, audio and video recording equipment (i.e., nonintrusive video camera and microphone), a desk and chair, and a desktop computer. All computer-facilitated activities utilized headphones to present uninterrupted audio content to participants. 


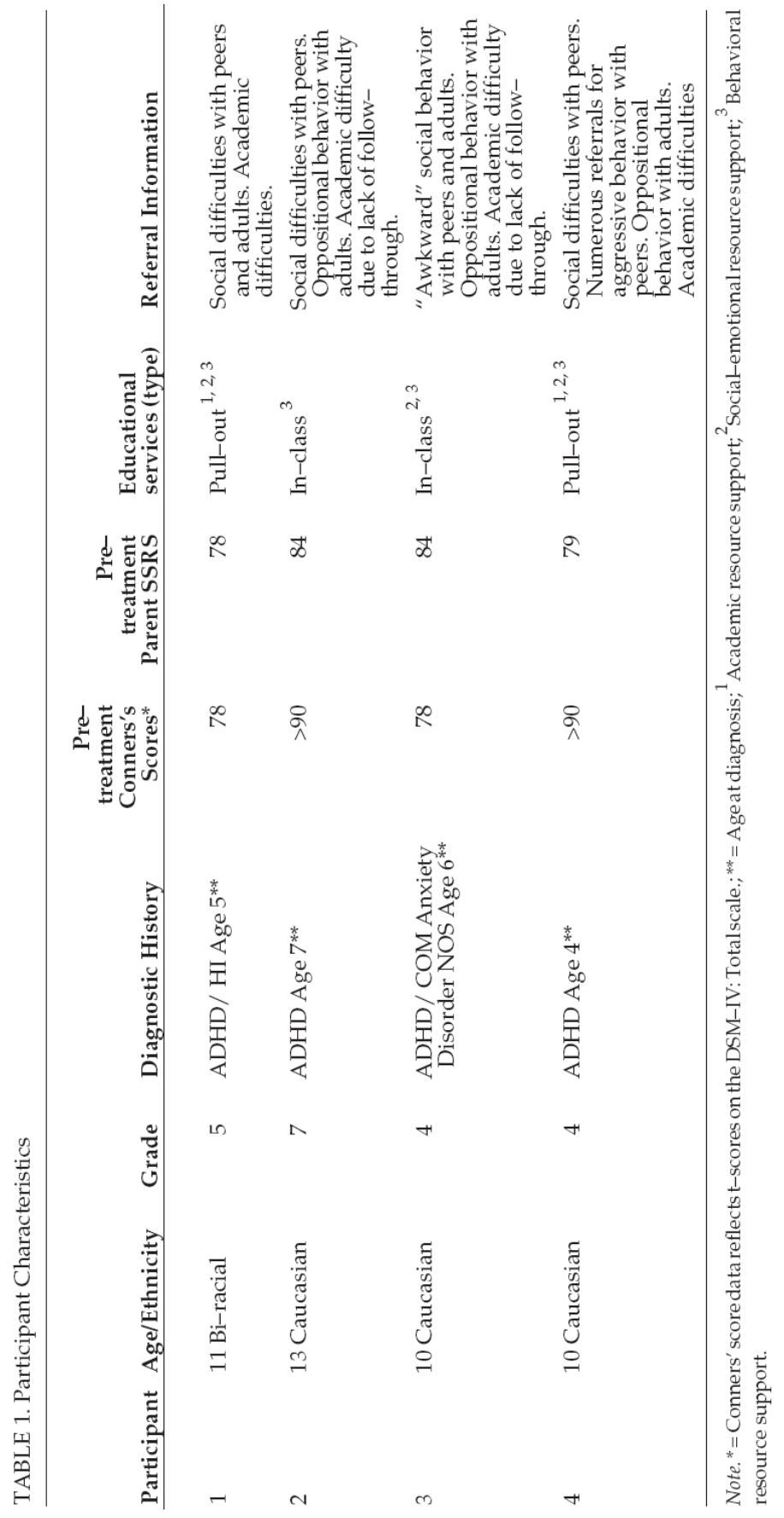




\section{Independent Variable}

An interactive computer-facilitated social skills training program developed by the first author using direct instruction with a feedback component served as the independent variable in this study. The social skills training content was based on a published curriculum (The Tough Kid Social Skills Book; Sheridan, 1995a). Training was conducted two times per week over a 6-week period with each session lasting approximately 50 minutes. A general problem-solving strategy was taught and generalized across three subskills (i.e., Accepting No, Solving Arguments, Using Self-Control) deemed problematic for children with ADHD (Guevremont, 1990; Sheridan, 1998). All computer-facilitated instruction was delivered by a videotaped peer actor, who served as a "virtual assistant," using a combination of video-and audio-formatted content viewed on a desktop computer. The videotaped peer actor was the same gender and approximate age as the participants. Salient aspects of training included videotaped modeling, computerfacilitated rehearsal, feedback, prompting, and reinforcement. These are described more fully in the section on treatment procedures below.

\section{Dependent Variables}

The primary dependent variable in this study was each participant's social problem-solving behavior exhibited during real-life, analogue role-playing situations using two trained confederate peers. These social problem-solving behaviors, listed and operationally defined in Table 2, served as criterion objectives. Behaviors were coded by trained observers using videotapes of each analogue role play. Parent ratings provided secondary measures of participants' social skills.

\section{Procedures}

Participants entered the clinic location and were initially greeted by a research assistant. They proceeded to a training/observation area where they were given specific instructions based on a Baseline, Treatment, or Follow-up protocol. Two confederate peers (a female, age 11 and a male, age 12) with no diagnosed disability or psychiatric condition, and who had no other contact with the participants, were recruited to participate in a series of scripted analogue role plays during Baseline, Treatment, and Follow-up phases. Each confederate peer was trained using verbal instruction, modeling, and behavioral rehearsal to ensure adherence to each analogue role-play script. During each phase of the study, participants also viewed several interactive, 
TABLE 2. Social Skill Problem-solving Substeps (Based on Previous Research of Sheridan, Dee, Morgan, McCormick, and Walker, 1996)

\begin{tabular}{|c|c|c|}
\hline & Skill Step & Definition \\
\hline \multirow[t]{5}{*}{1 (Body Basics) } & Face the Other Person & $\begin{array}{l}\text { Body is square to the other when appropriate, } \\
\text { or head turns toward other when in } \\
\text { conversation. }\end{array}$ \\
\hline & Use Eye Contact & $\begin{array}{l}\text { Eyes look into face of other in a comfortable } \\
\text { and appropriate manner, rather than on floor, } \\
\text { out window, or staring inappropriately. }\end{array}$ \\
\hline & $\begin{array}{l}\text { Maintain Appropriate } \\
\text { Physical Space }\end{array}$ & $\begin{array}{l}\text { Approximately two arm lengths away when } \\
\text { in conversation, or appropriately closer or } \\
\text { further when the situation calls for it (e.g.' } \\
\text { when whispering or playing a team sport). }\end{array}$ \\
\hline & $\begin{array}{l}\text { Maintain a Neutral } \\
\text { Body Posture }\end{array}$ & $\begin{array}{l}\text { Hands, arms, and legs appear loose and } \\
\text { relaxed and fists are not clenched. }\end{array}$ \\
\hline & $\begin{array}{l}\text { Use an Appropriate } \\
\text { Voice }\end{array}$ & $\begin{array}{l}\text { Voice is audible to those in immediate prox- } \\
\text { imity but not to persons at a distance of } 10 \\
\text { feet or more unless the situation calls for it. } \\
\text { Inflection in voice is appropriate to the } \\
\text { conversation rather than sarcastic or snide. }\end{array}$ \\
\hline 2 & $\begin{array}{l}\text { Wait for a Good Time } \\
\text { to Begin Problem- } \\
\text { solving Behavior }\end{array}$ & $\begin{array}{l}\text { Does not interrupt ongoing conversation or } \\
\text { activity such that behavior evokes negative } \\
\text { reaction from others. }\end{array}$ \\
\hline 3 & $\begin{array}{l}\text { Demonstrate Self- } \\
\text { Control }\end{array}$ & $\begin{array}{l}\text { Pauses approximately } 5 \text { seconds before } \\
\text { responding, takes a deep breath, refrains } \\
\text { from responding in an aggressive, } \\
\text { intrusive, or otherwise inappropriate } \\
\text { manner. This behavior must occur for the } \\
\text { majority of the interaction. }\end{array}$ \\
\hline 4 & $\begin{array}{l}\text { Demonstrate Recogni- } \\
\text { tion of the Problem }\end{array}$ & $\begin{array}{l}\text { Makes statements such as "Let's stop a min- } \\
\text { ute" or "We disagree about who goes first." }\end{array}$ \\
\hline 5 & $\begin{array}{l}\text { Offer or Demonstrate } \\
\text { One Alternative }\end{array}$ & $\begin{array}{l}\text { Makes a statement such as "Let's look at the } \\
\text { directions" or walks away from the } \\
\text { confrontational situation. }\end{array}$ \\
\hline 6 & $\begin{array}{l}\text { Offer or Demonstrate a } \\
\text { Second Alternative if } \\
\text { the First is Ineffective }\end{array}$ & $\begin{array}{l}\text { Makes a statement such as "Heads you go } \\
\text { first, tails I go first" or ignores child who is } \\
\text { teasing. This behavior can be non-applica- } \\
\text { ble if first alternative is effective. }\end{array}$ \\
\hline 7 & $\begin{array}{l}\text { End Interaction } \\
\text { Appropriately }\end{array}$ & $\begin{array}{l}\text { Provides a closing statement to the interac- } \\
\text { tion, such as "good-bye," "see you later," } \\
\text { "good game," or demonstrates and appro- } \\
\text { priate physical gesture such as a wave. }\end{array}$ \\
\hline
\end{tabular}

videotaped scenarios on a computer screen. Scenarios were assigned randomly to both Baseline and Follow-up conditions. The scenarios presented during Treatment were predetermined as the targeted subskill (e.g., Accepting No) for each particular session.

During Baseline, participants and confederates initially completed the analogue role plays (10 minutes) and then each participant viewed the series of interactive, computer-facilitated social scenarios without feedback (20 minutes). During the Treatment phase, participants (a) 
completed computer-facilitated direct instruction activities (20 minutes) presented by the videotaped peer actor, (b) viewed the interactive, videotaped social scenarios with feedback (20 minutes) on the same computer, and (c) participated in a series of live, analogue role plays with each of the confederate peers (10 minutes). During Followup, participants again completed the interactive, computer-facilitated social scenario without feedback (20 minutes) and the analogue role plays (10 minutes). At the conclusion of each session, participants returned to the waiting room. Reinforcement for performance during the computer training (if applicable) was then provided to the participants. More specific information regarding each experimental condition is provided below.

Baseline. Each baseline session included specific procedures to assess each participant's problem-solving skills during analogue role plays. Baseline data were collected over four sessions. During each session, each participant interacted in two randomly selected role-play situations with a similar-aged peer. After completing two role plays, participants viewed four to six interactive, video-based social scenarios and were given an opportunity to select a preferred response to each situation. Each scenario was presented with no direct skill instruction or direct feedback about performance.

Treatment. Each training session provided instruction on various social skills and their components and multiple opportunities for the participant to view and respond to video scenarios illustrating a variety of social interactions requiring an application of those skills. Each of the six 50-minute training sessions included a brief introduction to the computer program, and the social skills training package. The training package required each participant to view a videotaped peer actor who demonstrated specific problem-solving strategies and skill components. Instruction on these topics closely followed approaches outlined in The Tough Kid Social Skills Book (Sheridan, 1995a) and is detailed further below. Each strategy was then reviewed using components of an animated classroom environment (e.g., chalk and chalkboard, narrated voice-over, television). The sequence was replicated across each problem-solving subskill (i.e., Solving Arguments, Using Self-Control, and Accepting No) so that each skill was presented two times during the treatment phase (Sheridan \& Walker, 1999; Sheridan, Hungelmann, \& Maughn, 1999).

Modeling. Each participant viewed the videotaped peer actor who provided direct instruction and modeled the use of the targeted problem-solving subskills. Specifically, the videotaped peer actor identified numerous social situations that would require the use of the targeted 
subskill and then demonstrated the use of the skill through verbalization of the subskill steps and appropriate behavioral responses. Visual examples were reinforced by a computer-generated blackboard that reviewed each presented skill and subskill.

Video scenarios. Participants then viewed a series of interactive scenarios that presented "real-world" video content depicting social situations that required the participant to select one of several response options. Each scenario used natural settings (e.g., classroom, playground) and age-appropriate peers. The situations were multistage, responsedriven scenarios reflecting realistic events requiring a skill (e.g., Accepting No) and consequences to each participant's responses. Thus, depending on the specific response, alternative consequences were depicted that required subsequent behavioral choices and decisionmaking to further negotiate the interaction. During this specific component, the computer program provided no instruction or assistance, only opportunities to view the scenario and indicate a specific choice.

Feedback and reinforcement. Participant responses during these video scenarios produced computer-generated feedback regarding skill use, provided prompts for appropriate response choices, and administered reinforcement. Immediate feedback was provided via a point monitoring system for each time the student identified and selected a response. Each of the participant's forced-choice responses was scored based on a rank-order value determined by expert reviewers. Decisions indicating appropriate understanding and use of the targeted social skills during the program received higher point totals. The system monitored earned points throughout each stage, and the total score was displayed at the end of each training session. Once participants had completed each of the social skills training sessions, they were given the opportunity to exchange the earned points for a reinforcer.

Follow-up. Follow-up data using both the analogue role-play assessments and completion of the interactive, computer-facilitated social scenarios were collected at 3 and 6 weeks post-intervention for each student. Specifically, each participant returned to the site of the study to participate in a series of analogue role plays using the same confederate peers. They also viewed a selection of interactive, computerfacilitated scenarios presented during the first and second sessions of the Baseline phase. No prompting, direct skill training, or feedback occurred during this time.

\section{Assessment Methods and Procedures}

A multimethod, multisource assessment methodology was used and included assessment of participants' behaviors in analogue settings and behavioral ratings of social skills. 
Social behaviors in analogue settings. Direct observations of social skills demonstrated by each participant during analogue role plays were conducted two times per session during Baseline (four sessions), Treatment (six sessions), and Follow-up (two sessions). The analogue role plays preceded computer-facilitated training during Baseline and immediately followed computer-facilitated training during the intervention and Follow-up phases. The seven identified subskills of problem solving (see Table 2) were assessed via videotaped observations of the participants' behavior during structured role-play scenarios with a peer confederate. Raters used the Social Skills Behavioral Checklist: Analogue Observations Form (Sheridan, 1993), which is a direct observational method designed to measure discrete components of social skills (i.e., social problem solving) as they occur in an analogue, role-play environment (Sheridan et al., 1996). Two raters (one undergraduate student studying psychology and one graduate student studying school psychology) were trained to mastery by the first author to identify each of the problem solving substeps presented in Table 2. Raters then viewed sample videotapes of social interactions and rated the presence of the problem solving substeps until they achieved $85 \%$ or higher agreement.

Raters indicated the occurrence or nonoccurrence of the seven subskills as demonstrated by the participants during each of the analogue sessions (Sheridan et al., 1996). The total percentage of skill components demonstrated during each role play was determined and reported. Interrater reliability was computed across two independent raters blind to experimental conditions using both a percent agreement formula (i.e., number of agreements divided by the number of agreements and disagreements, multiplied by 100) and the kappa statistic on $33 \%$ of the analogue role plays (randomized across participants and conditions).

Ratings of social behavior. The Social Skills Rating System (SSRS; Gresham \& Elliott, 1990) is a multisource, multidimensional rating scale system that was administered to participants and their parents prior to and following the study. All scales (i.e., Social Skills and Problem Behaviors) have a mean of 100 and a standard deviation of 15 with higher scores indicating greater levels of social competence and lower scores associated with deficiencies. The parent and student forms of the SSRS contain 38 and 34 items, respectively. Factor analysis has revealed three common factors: Cooperation, Assertive Behavior, and Self-Control. In addition, the parent form (SSRS-P) has the factor of Responsibility and the student form (SSRS-S) has the factor of Empathy. The SSRS was selected for use in this study due to its high test-retest reliability for the parent form $(r=.87)$ and adequate test-retest reliability for the student 
form $(r=.68)$. It has been used extensively in social skills research and is believed to be sensitive to treatment effects (Sheridan et al., 1996).

Social validity. Social validity is an awareness and concern for the clinical meaningfulness and applied importance of behavior change (Kazdin, 1977). Two forms of social validity were assessed in this study: treatment acceptability and subjective evaluation of effectiveness. To determine treatment acceptability, each participant's parent completed the Behavior Intervention Rating Scale (BIRS; Von Brock \& Elliott, 1987) to assess perceptions of the acceptability of the social skills intervention. The BIRS is a 24 -item scale that utilizes a 6 -point Likert scale that indicates the degree to which the respondent agrees or disagrees with the presented statements. Individual scores on this measure can range from 24 to 144 . The BIRS was selected because of its documented internal consistency (Von Brock \& Elliott, 1987) and factorial validity (Elliott \& Treuting, 1991). The three factors supported by factor analysis include acceptability (15 items), effectiveness (6 items), and time to effectiveness ( 2 items). For a review of the psychometric properties of the BIRS, the interested reader is referred to Finn and Sladeczek (2001). As suggested by Gresham (1986), individuals in the child's environment can assess social validity through subjective evaluation of target behavior change. The BIRS is commonly used to provide this evaluation of a given intervention. For this study, the eight questions combined from the "effectiveness" and "time to effectiveness" factors on the BIRS were used to assess the perceived effectiveness of the computer-facilitated social skills intervention program and to assess the degree to which the intervention was associated with meaningful changes in their child's social behavior.

To assess students' acceptability of the intervention, each participant completed the Child Intervention Rating Profile (CIRP; Witt \& Elliott, 1985). The CIRP is a seven-item questionnaire that was used to evaluate each participant's perception of the acceptability of the intervention procedures. The CIRP utilizes a 7-point Likert scale to assess the degree to which the intervention was acceptable and fair and to determine if any side effects were present. Although limited psychometric support is available (Finn \& Sladeczek, 2001), this scale was selected because of its use in clinical settings and its reported effectiveness in conveying children's acceptability of treatments (Witt \& Elliott, 1985). Items from the CIRP were slightly modified to refer specifically to the current study and to replace the 7 -point scale format with a 5-point scale.

\section{Experimental Design}

A multiple probe variation of the multiple-baseline design (MBD) across participants was used. Three series (one participant in each of 
the first two series and two paired in the third) were included. Instruction of social problem-solving skills was implemented in a staggered fashion across the three series. Follow-up data were collected at three and six weeks post-intervention for each participant.

Data collected through direct observation procedures were analyzed both within and across participants. Visual analysis procedures and effect size measures were utilized to evaluate treatment effects. In addition, data collected from treatment acceptability and social validity measures reported descriptively. Effect sizes for each participant were computed based on established statistical procedures to evaluate and quantify the intervention's overall effectiveness (Busk \& Serlin, 1992). Separate effect sizes were calculated for each participant by dividing the difference between Baseline and Treatment phase means by the Baseline standard deviation (Glass, 1976). According to Forness, Kavale, Blum, and Lloyd (1997), an effect size is considered "potentially significant" at .40 and "compelling" when it reaches a value of .60 or greater.

\section{RESULTS}

\section{Behavioral Demonstration of Social Problem-solving Skills}

A summary of the mean percentage of problem-solving skill components and standard deviations across participants and phases is presented in Table 3. Figure 1 illustrates participants' individual data series across each condition. All participants demonstrated increases in mean levels of social problem-solving skill performance from Baseline to Treatment, with average increases ranging from $8 \%$ to $39 \%$. Effect sizes ranged from .55 to 1.74 (mean effect size $=1.17$ ). With the exception of Participant 3, each student demonstrated moderate to low levels of overlapping data. Furthermore, all participants maintained their improved skill performance at 3- and 6-week follow-up assessments.

Overall interrater agreement was established using two raters who viewed an identical set of $33 \%$ of all videotaped analogue assessments. Each participant and experimental phase was presented in the reliability scenarios, and raters were blind to experimental condition. Using the percent agreement formula, the percent agreement across raters was calculated to be $85.80 \%$. The kappa statistic was also calculated to provide a more rigorous correction for chance agreement between observers and resulted in a chance corrected proportion of agreement of $.46(n=352 ; p<.001)$. Given the number of paired ratings, this represents an acceptable level of agreement (Sattler, 2002). 
TABLE 3. Mean Percentage of Problem-solving Subskills in Analogue Assessment across Baseline, Treatment, and Follow-up Phases

\begin{tabular}{lrrrrrr}
\hline Participant & $\begin{array}{r}\text { Baseline } \\
\text { Mean (SD) } \\
\text { across four } \\
\text { sessions }\end{array}$ & $\begin{array}{r}\text { Treatment } \\
\text { Mean (SD) } \\
\text { across six } \\
\text { sessions }\end{array}$ & Difference & $\begin{array}{r}\text { Effect } \\
\text { Size }\end{array}$ & $\begin{array}{r}\text { Follow-up } \\
\text { Mean (SD) } \\
\text { across two } \\
\text { sessions }\end{array}$ & $\begin{array}{r}\text { PND } \\
\text { overlapping } \\
\text { data points) }\end{array}$ \\
\hline 1 & 41.01 & 79.74 & 38.73 & 1.74 & 82.15 & $66.7 \%$ \\
& $(22.20)$ & $(12.87)$ & & & $(21.45)$ & \\
2 & 58.88 & 82.12 & 23.24 & 1.30 & 100 & $66.7 \%$ \\
& $(17.82)$ & $(10.77)$ & & & $(0.0)$ & \\
3 & 78.55 & 86.89 & 8.34 & .55 & 100 & $16.67 \%$ \\
& $(15.29)$ & $(12.87)$ & & & $(0.0)$ & \\
4 & 62.46 & 85.70 & 23.24 & 1.08 & 89.28 & $66.7 \%$ \\
& $(21.53)$ & $(12.19)$ & & & $(7.15)$ & \\
\hline
\end{tabular}

Note. Numbers in parentheses reflect standard deviations. Difference $=$ Difference between treatment and baseline means. PND = Percent of nonoverlapping data between baseline and treatment.

\section{Ratings of Global Social Skills}

Pre- and post-treatment Social Skills Rating System data collected from parents and students prior to and following treatment were calculated. The overall SSRS mean across parent responses at pre-intervention was

81.25 (range $=78-84 ; S D=3.20$ ); the post-intervention mean was 86 (range $=75-98 ; S D=9.48$ ). Whereas the parents of Participants 2 and 4 demonstrated minimal increases in their standard scores, Participant 3's parent rated him nearly one standard deviation higher from pre- to post-intervention. Participant 1's standard score decreased minimally from pre- to post-intervention.

The average student pre-intervention SSRS standard score was 98.50 (range $=92-114 ; S D=10.37$ ); the post-intervention average was 109.28 (range $=93-121 ; S D=13.22$ ). Whereas all participants' standard scores demonstrated an increase, most notably Participant 1's SSRS self-rating increased 1.8 standard deviations from pre- to post-intervention.

\section{Social Validity}

Treatment acceptability was assessed for all parents and participants in the study. Specifically, parents rated the acceptability and effectiveness of the computer-facilitated social skills intervention using the Behavior Intervention Rating Scale (BIRS; Von Brock \& Elliott, 1987). Parents' overall mean item rating on the Acceptability factor was 5.40 (range $=$ 5.13-5.66 on a scale of 1-6), indicating that the intervention was quite acceptable to parents. The average rating on the Effectiveness factor, as- 


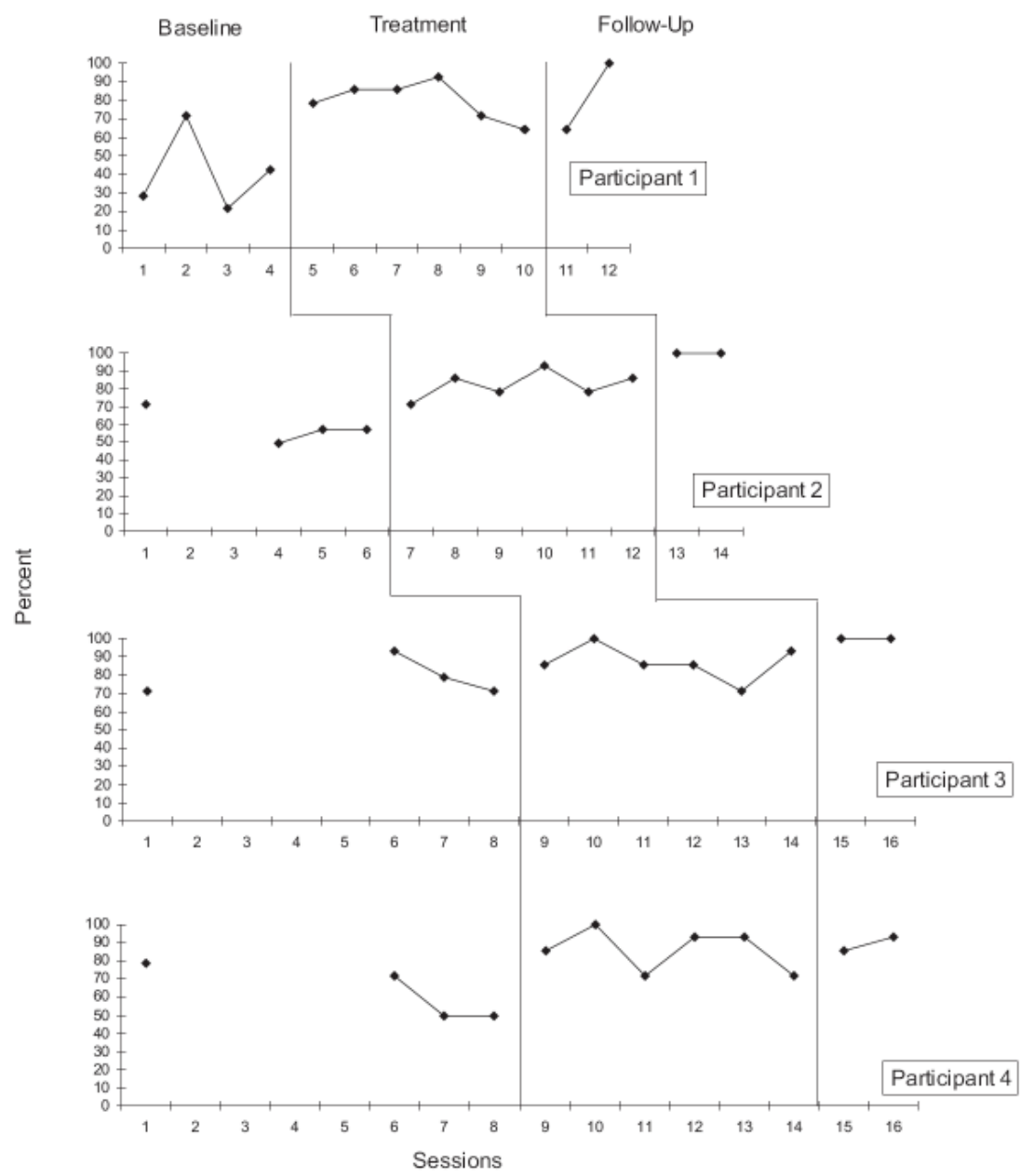

Figure 1. Percentage of problem-solving skills demonstrated by participants during behavioral analogue role-play assessments across phases of the study.

sessing parents' subjective ratings of the effectiveness of the intervention, was 3.54 (slightly effective; range $=3.14-4.14$ ). Although parents viewed the intervention's acceptability in very favorable terms, they were less certain concerning its effectiveness.

The child participants rated their perceptions of the acceptability of the computer-facilitated social skills program using the Children's In- 
tervention Rating Profile (CIRP; Witt \& Elliott, 1985). Items from the CIRP were rated on a five-point Likert scale with low scores reflecting high levels of acceptability ( $1=\mathrm{I}$ agree very much; $5=\mathrm{I}$ mostly disagree). The mean score across participants was 1.28 , indicating that the participants perceived the intervention as highly favorable and acceptable.

\section{DISCUSSION}

The results of this study indicated that children with ADHD who participated in an interactive, computer-facilitated social skills training program demonstrated and maintained gains in behavioral enactment of social problem-solving skills as assessed during analogue observations. Improvement in demonstrated problem-solving subskills during the analogue role-play assessments was evident for all participants. In addition, decreases in variability during treatment were noted for all participants, and treatment gains were generally maintained at 3 and 6-week follow-ups. Analysis of phase mean and standard deviation changes, immediacy of change following condition changes, and data trends within the multiple-baselines-across-participants design suggest that an adequate level of experimental control was attained (Tawney \& Gast, 1984). Results are consistent with previous work by Sheridan and colleagues (1996), who reported similar improvement in children's demonstration of problem-solving behavior during analogue role-play assessments using more traditional social skill interventions.

Some differential results across participants were also evident. For example, relatively smaller mean increases were noted for Participant 3. This could be attributed to higher rates of demonstrated skill during Baseline and anxious behaviors that were apparent during the preparation and completion of the behavioral analogue assessments (e.g., increased stuttering and stammering, biting fingers, long verbal pauses, and reduction in nonverbal responses to the investigator). This behavior was consistent with his comorbid anxiety NOS diagnosis. Participant 3 stated on several occasions that he "didn't like the role plays" because they made him "nervous." Although Participant 3 appeared to become increasingly calm with continued exposure to the role plays, his comparatively heightened anxiety was evident throughout the sessions and may have interfered with his overall performance of acquired skills during the analogue role plays. This behavior is similar to what Gresham (1988) characterizes as a physiological-emotional response mode.

Interestingly, parents' ratings of participants' social skills on the SSRS-Parent Form as a group were not substantially different from pre- to post-treatment ( $+/-5$ points). This finding contrasts markedly with the participants' increase in total scores on the self-rated SSRS Student Form. From the parental perspective, the relatively short dura- 
tion and low frequency (two times per week) of exposure to the computer-facilitated intervention may have been insufficient to promote generalization of social skills demonstrated in analogue settings to natural environments (Bosworth, Espelage, \& Dubay, 1998; Bryson, 1999), or to alter parental perceptions of each child's behavior. Conversely, the overall gains perceived by the participants may in fact, be associated with a general increase in participants' self-image and, subsequently, their perceived social competence. These findings are consistent with other research indicating that problem-solving-based social skills training may have positive effects on the self-esteem and selfperception of children with ADHD (Lyons, 2000; Russomano, 2000).

Consistent with somewhat equivocal ratings on the SSRS-Parent Form, parents found the computer-facilitated social skills intervention used in this study as favorable and acceptable, but only moderately effective in addressing their child's social skills problems. Written comments from all of the participants' parents indicated a desire for a longer intervention, and two requested the program to implement the intervention within the home environment. Interestingly, subsequent to the study and after he returned to school, Participant 1's parent indicated a noticeable decrease in reported problem behaviors at school and stated, " His teacher actually sees him stop and think before he acts now." Parents may in fact feel more confident in their perceptions of behavior change when they are confirmed or validated by other adults in the child's environment.

Participants viewed the intervention in very positive terms. It is likely that this favorable view of their experience was influenced in part by the prominence of computer and video games in the daily lives of children. The structured and predictable nature of the video game environment (e.g., clear rules, time limits, sharing with peers) may allow children who have difficulty managing more complex social situations the opportunity to learn skills facilitating successful interactions with peers within a controlled environment. In addition, parents may have viewed the intervention as potentially flexible and easy to implement at both home and school.

\section{Contributions of the Present Study}

The present study afforded an opportunity to evaluate an interactive, computer-facilitated social skills training intervention addressing social problem-solving skills in children with ADHD via direct skill instruction and multistage, response-driven social scenarios. Although computer-facilitated technology has been used by researchers to assess and intervene in a variety of areas (e.g., Bosworth et al., 1998; Irvin \& Walker, 1994; Kass et al., 1994; Matthys et al., 1999), virtually no 
programs known to the authors have targeted the actual development of social problem-solving skills. Given that children with ADHD often exhibit delays in social-relatedness skills (DuPaul et al., 2001; Sheridan, 1998), this study has demonstrated that an interactive, computer-facilitated social skills intervention can successfully assist children in their ability to acquire knowledge of social skills steps, and to use these social problem-solving skills in behavioral analogue role plays. The computer-facilitated social and instructional environment for this study provided a bridge between knowledge acquisition and behavioral enactment of social skills thereby allowing each participant to explore potential consequences of his or her behavior within a structured, supportive, and controlled environment.

This study contributes to the growing literature base on the assessment, treatment, and generalization of social skills deficits, particularly in children and adolescents with ADHD. The intervention employed in this study utilized interactive videotaped scenarios that incorporated relevant environmental factors including ecological events (e.g., context-specific social rules, environmental cues regarding expected social behavior, and sequences of events and social interactions that serve as antecedents to specific situations), verbal and nonverbal interpersonal communication, realistic response choices, and related social consequences. A variety of techniques known to influence the development and use of social skills, including aspects of social modeling, coaching, role playing, reinforcement, self-talk, relaxation skills, and natural and logical consequences were represented in the intervention as well (e.g., Bullis, Walker, \& Sprague, 2001; Colton \& Sheridan, 1998; Gresham \& Elliott, 1993; Michelson, Sugai, Wood, \& Kazdin, 1983; Sheridan et al., 1996). This approach is also consistent with the recently completed Multimodal Treatment for ADHD (MTA) project, which supports the use of multiple behavioral, cognitive behavioral, and social learning techniques to affect children's social behavior (Wells et al, 2000). Finally, the use of more individualized instruction to remediate social skills deficits is more flexible and may avoid the unintended consequences associated with group-based interventions (Arnold \& Hughes, 1999; Dishion et al., 1999).

\section{Limitations of the Present Study}

Several limitations of the study must also be considered. An important limitation lies in the lack of measures to evaluate generalization of social problem-solving skills targeted in this intervention to natural environments such as school settings. Although anecdotal information and rating scales provided by parents indicated improvements in social behavior for some participants, no objective behavioral out- 
come data were collected outside of the experimental setting. Numerous authors (DuPaul \& Eckert, 1994; Elliott \& Gresham, 1993; Merrell \& Gimpel, 1998; Sheridan et al., 1996; Sheridan et al., 1999; Sheridan \& Walker, 1999) have argued that the validity of social skills interventions is questionable unless generalization of the targeted skills to other natural environments can be demonstrated. Given that the current investigation evaluated the generalization of skills from computer-facilitated instruction to behavior-based, analogue role plays, further exploration of participants' abilities to transfer skills from an analogue to a naturalistic environment is a necessary next step.

Second, there was a general lack of stability and increasing trend in Baseline data for the behavioral analogue data for Participant 1 . The variability and increasing Baseline trends noted in the data are potential threats to the internal validity of the multiple-baseline design (MBD) and may limit conclusions regarding outcomes (Tawney \& Gast, 1984). However, the need to implement treatment in a timely fashion required the need for compromise between methodological rigor and applied research practices. Specifically, condition changes were implemented before achieving desired levels of stability in Baseline data.

A third limitation involves the high levels of Baseline skills represented in behavioral analogue data for Participant 3. Although participants met selection criteria for inclusion in the study based on their first completed behavioral analogue assessment probes, this participant demonstrated relatively high mean skill performance throughout Baseline. These higher than anticipated Baseline levels may affect the ability of the research design to represent meaningful changes in targeted behaviors. Future research should consider selection criteria based on multiple or repeated probes rather than a single observation.

Finally, participants were repeatedly exposed to the computer training environment, research assistants, confederate peers, and analogue role-play situations. Observations of participants' behaviors during the study showed that later sessions were characterized by an increase in experimentation with the computer hardware and software, off-task behavior, and less serious interactions before and during the structured role plays. For example, Participant 1 required repeated redirection from research assistants to curb his exploration and dismantling of the computer hardware during treatment. The behavior of participants 2 and 4 during the analogue role plays became less formal and increasingly playful throughout the study. On several occasions, Participant 2 attempted to reverse the assigned roles during the presentation of the role-play instructions and stated, "I want to do his part this time" and "I get to tell you what to do this time." Numerous prompts, 
redirection, and reinforcement were successfully implemented to assure compliance with instructions and appropriate participation in the role plays, and peer confederates were instructed to avoid casual conversations with the participants before and following the role plays to limit familiarity with the participants. The experience does suggest the need to monitor student activities closely.

\section{Future Research Needs}

Although there are numerous social skills interventions available to professionals, the use of interactive computer-facilitated training programs is unique. There is a need to further investigate the effectiveness of computer-facilitated social skills training for children with ADHD in real-world situations or otherwise more naturalistic environments. While the use of behavioral analogue and role-play-type situations is helpful, the real test of an intervention's utility needs to be established in those naturalistic situations. Further research should employ direct observation and related assessment protocols in "real-world" environments and situations to examine the intervention's effects on social competence (Sheridan \& Walker, 1999).

Another line of study should examine the use of this intervention with additional participants and different participant populations across a variety of environments (i.e., home, school) and target behaviors. Given that delayed social skills have been identified in several populations (e.g., behavior-disordered, traumatic brain injury, social/school phobia, early childhood), expansion of this intervention to meet the needs of various populations is warranted. For example, preschool children with ADHD are at significant risk for behavioral, academic, and social problems (DuPaul et al., 2001). While the current intervention was developed to address the social problem-solving skills of children 10 years and older, further application with younger children may prove to be an effective means of increasing early prosocial knowledge and behavior.

Studies using comparative research designs to contrast technologysupported and group-based treatment are also needed. Studies comparing the effectiveness of differing intervention strategies for children with ADHD are numerous (e.g., Greene \& Ablon, 2001; Hinshaw et al., 2000; MTA Cooperative Group, 1999). Future studies might directly compare a group of participants exposed only to the computer-facilitated intervention with one that provides participants with a traditional group experience. Additional research might pair the traditional group instruction model with the software package to supplement the in-group activities. Contrasting this combination of interventions with a group-based-only or a computer-facilitated-only treatment 
approach would provide opportunities to evaluate the most effective means of utilizing the program.

There continues to be a need to evaluate how social skills are measured, including studies that evaluate the reliability and validity of the Social Skills Observation System and the use of role-play scenarios. Research thoroughly examining the psychometric properties of this coding system and standardized procedures for training coders would improve future social skills research. Although the face validity of the analogue role-play scenarios used in this system is high, it is not clear that they accurately measure the construct of social problem solving (Sheridan et al., 1996).

Finally, expanding the current intervention strategy to actively involve both parents and peers would be a valuable line of research. Joint parent-child participation in social skills intervention has produced positive results (Sheridan et al., 1996; Wells et al., 2001). Using parents to encourage and reinforce learned skills, actively model skills presented in the program, and coach children in appropriate problem solving as they attempt the interactive scenarios would likely improve overall outcomes. Incorporating computer-facilitated intervention strategies into current intervention practice with families could potentially provide multiple opportunities to learn, practice, implement, and ultimately generalize targeted social skills to a wider variety of naturalistic situations.

\section{Implications for Practice}

The interactive, computer-facilitated social skills intervention used in this study appears to have promise for use by school psychologists, teachers, parents, and other professionals to address the social problem-solving difficulties that children with ADHD often experience. The success of the intervention is likely due to the extensive effort made during the development of the intervention to ensure that the training was socially valid and the use of a multimethod, multimodal (e.g., coaching, modeling, rehearsal, feedback) instructional environment to facilitate acquisition and performance of the desired skills.

The development of computer-facilitated video scenarios that approximate social environments and the range of choices within those environments is a promising development in the use of technology to support treatment of social skills difficulties for children with ADHD. Given the widespread use of computer-facilitated technology within the education system, this intervention could potentially increase the number of children who can access a social skills intervention at any one time, promote generalization of skills to other settings, and also create opportunities for parents to support training in home environments. 


\section{References}

American Psychiatric Association. (1994). Diagnostic and statistical manual of mental disorders (4th ed.). Washington, DC: Author.

Anastopoulos, A. D., DuPaul, G. J., \& Barkley, R. A. (1991). Stimulant medication and parent training therapies for attention deficit-hyperactivity disorder. Journal of Learning Disabilities, 24(4), 210-218.

Ang, R. P., \& Hughes, J. N. (2002). Differential benefits of skills training with antisocial youth based on group composition: A meta-analytic investigation. School Psychology Review, 31, 164-186.

Arnold, M.E., \& Hughes, J.N. (1999). First do no harm: Adverse effects of grouping deviant youth for social skills training. Journal of School Psychology, 37, 99-115.

Barkley, R. A. (1998). Attention deficit hyperactivity disorder. In E. J. Mash \& R. A. Barkley (Eds.), Treatment of childhood disorders (pp. 39-72). New York: The Guilford Press.

Barkley, R. A. (1990). Attention-deficit hyperactivity disorder: A handbook for diagnosis and treatment. New York: The Guilford Press.

Barkley, R. A., Fischer, M., Newby, R., \& Breen, M. (1988). Development of multimethod clinical protocol for assessing stimulant drug responses in ADHD children. Journal of Clinical Child Psychology, 7, 14-24.

Bosworth, K., Espelage, D., \& Dubay, T. (1998). A computer-based violence prevention intervention for young adolescents: Pilot study. Adolescence, 33(132), 785-795.

Bryson, R. (1999). Effectiveness of refusal skills software. Journal of Drug Education, 29(4), 359-371.

Bullis, M., Walker, H. M., \& Sprague, J. R. (2001). A promise unfulfilled: Social skills training with at-risk and antisocial children and youth. Exceptionality, 9(1), 67-90.

Busk, P. L., \& Serlin, R. C. (1992). Meta-analysis for single-case research. In T. R. Kratochwill \& J. R. Levin (Eds.). Single-case research designs and analysis: New directions for psychology and education (pp.187-212). Mahwah, NJ: Lawrence Erlbaum Associates.

Carroll, A., Bain, A., \& Houghton, S. (1994). The effects of interactive vs. linear video on the levels of attention and comprehension of social behavior by children with attention disorders. School Psychology Review, 23, 29-43.

Colton, D. L., \& Sheridan, S. M. (1998). Conjoint behavioral consultation and social skills training: Enhancing the play behavior of children with attention deficit hyperactivity disorder. Journal of Educational and Psychological Consultation, 9, 3-28.

Connors, C. K. (1989). Connors Rating Scales. North Tonawanda, NY: Multi Health Systems.

Dishion, T.J., McCord, J., \& Poulin, F. (1999). When interventions harm: Peer groups and problem behavior. American Psychologist, 54, 755-764.

DuPaul, G. J., \& Eckert, T. L. (1994). The effects of social skills curricula: Now you see them, now you don't. School Psychology Quarterly, 9, 113-132.

DuPaul, G. J., McGoey, K.E., Eckert, T.L., \& VanBrakle, J. (2001). Preschool children with attention-deficit/hyperactivity disorder: Impairments in behavioral, social, and school functioning. Journal of the American Academy of Child and Adolescent Psychiatry, 40, 508-515.

DuPaul, G.J., \& Stoner, G. (2003). ADHD in the schools: Assessment and intervention strategies (2nd ed.). New York: The Guilford Press. 
Edelbrock, C., Costello, A. J., \& Kessler, M. D. (1984). Empirical corroboration of the attention deficit disorder. Journal of the American Academy of Child Psychiatry, 23, 285-290.

Elliott, S. N., \& Treuting, M.V. (1991). The Behavior Intervention Rating Scale: Development and validation of a pre-treatment acceptability and effectiveness measure. Journal of School Psychology, 29, 43-51.

Elliott, S. N., \& Gresham, F. M. (1993). Social skills interventions for children. Behavior Modification, 17, 287-313.

Elliott, S. N., Gresham, F. M., \& Heffer, R. W. (1987). Social skills interventions: Research findings and training techniques. In C. S. Maher \& J. Zins (Eds.), Psychoeducational interventions in the schools (pp. 141-159). New York: Pergamon Press.

Finn, C. A., \& Sladeczek, I. E. (2001). Assessing the social validity of behavioral interventions: A review of treatment acceptability measures. School Psychology Quarterly, 16, 176-206.

Forness, S. R., Kavale, K. A., Blum, I. M., \& Lloyd, J. W. (1997). Mega-analysis of meta-analyses: What works in special education and related services. Teaching Exceptional Children, 29, 4-9.

Glass, G. V. (1976). Primary, secondary, and meta-analysis of research. Educational Researcher, 5, 3-8.

Greene, R. W., \& Ablon, J. S. (2001). What does the MTA study tell us about effective psychosocial treatment for ADHD? Journal of Clinical Child Psychology, 30, 114-121.

Gresham, F. M. (1986). Conceptual issues in the assessment of social competence in children. In P. S. Strain, M. J. Guralnick, \& H. M. Walker (Eds.) Children's social behavior: Development, assessment, and modification (pp. 143-179).New York: Academic Press.

Gresham, F. M. (1988). Social skills: Conceptual and applied aspects of assessment, training, and social validation. In J. C. Witt, S. N. Elliott, \& F. M. Gresham (Eds.), Handbook of behavior therapy in education (pp. 523-546). New York: Plenum Press.

Gresham, F. M. (2002). Teaching social skills to high risk children and youth: Preventive and remedial strategies. In M.R. Schinn, H.M. Walker, \& G. Stoner (Eds.), Interventions for academic and behavior problems II: Preventative and remedial approaches. (2nd ed., pp. 403-432). Washington, DC: National Association of School Psychologists.

Gresham, F. M., \& Elliott, S. N. (1990). The Social Skills Rating System. Circle Pines, $\mathrm{MN}$ : American Guidance Services.

Gresham, F. M., \& Elliott, S. N. (1993). Social Skills Intervention Guide: Systematic approaches to social skills training. Special Services in the Schools, 8, 137-158.

Guevremont, D. (1990). Social skills and peer relationship training. In R.A. Barkley (Ed.), Attention deficit hyperactivity disorder: A handbook for diagnosis and treatment (pp. 540-572). New York: The Guilford Press.

Hinshaw, S. P., Owens, E. B., Wells, K. C., Kraemer, H. C., Abikoff, H. B., Arnold, L.E., et al., (2000). Family processes and treatment outcome in the MTA: Negative/ineffective parenting practices in relation to multimodal treatment. Journal of $A b$ normal Child Psychology, 28, 555-568.

Holsbrink-Engels, G. A., (1997). Computer-based role-playing for interpersonal skills training. Simulation and Gaming, 28(2), 164-180.

Hoza, B. (2001). Psychosocial treatment issues in the MTA: A reply to Greene and Ablon. Journal of Clinical Child Psychology, 30, 126-130. 
Hoza, B., Owens, J. S., \& Pelham, W. E. (1999). Attention-deficit/hyperactivity disorder. In R. T. Ammerman, M. Hersen, \& C. G. Last (Eds.), Handbook of prescriptive treatments for children and adolescents. Needham Heights, MA: Allyn \& Bacon.

Irvin, L. K., \& Walker, H. M. (1994) Assessing children's social skills using computerbased microcomputer technology. Exceptional Children, 61, 182-196.

Kass, A., Burke, R., Blevis, E., \& Williamson, M. (1994). Constructing learning environments for complex social skills. Journal of the Learning Sciences, 29, 226-237.

Kazdin, A. E. (1977). Assessing the clinical or applied importance of behavior change through social validation. Behavioral Modification, 1, 427-452.

Klein, R. G., \& Manuzza, S. (1991). Long-term outcomes of hyperactive children: A review. Journal of the American Academy of Child and Adolescent Psychiatry, 30, 383-387.

Lahey, B. B., Schaughency, E. A., Hynd, G. W., Carlson, C. L., \& Nieves, N. (1987).Attention deficit disorder with and without hyperactivity: Comparison of behavioral characteristics of clinic referred children. Journal of the American Academy of Child Psychiatry, 26, 718-723.

Lyons, J. I. (2000). Effects of social skills training on self perception in eight-to-sixteen year-old outpatient clients. (Doctoral dissertation, University of Hartford, 2000) Dissertation Abstracts International, 60(12-B), 6373.

Margalit, M. (1995a). Social skills learning for students with learning disabilities and students with behaviour disorders. Educational Psychology, 15, 445-456.

Margalit, M. (1995b). Effects of social skills training for students with an intellectual disability. International Journal of Disability, Development and Education, 42, 75-85.

Margalit, M., \& Weisel, A. (1990). Computer-assisted social skills learning for adolescents with mild retardation and social difficulties. Educational Psychology, 15, 445-456.

Matthys, W., Cuperus, J. M., \& Van Engeland, H. (1999). Deficient social problem solving in boys with $\mathrm{OCD} / \mathrm{CD}$, with $\mathrm{ADHD}$, and with both disorders. Journal of the American Academy of Child and Adolescent Psychiatry, 38, 311-321.

Merrell, K. W., \& Gimpel, G. A. (1998). Social skills of children and adolescents: Conceptualization, assessment, treatment. Mahwah, NJ: Lawrence Erlbaum Associates, Inc.

Michelson, L., Sugai, D., Wood, R., \& Kazdin, A. E. (1983). Social skills assessment and training with children and adolescents. New York: Plenum Press.

MTA Cooperative Group. (1999).A 14-month randomized clinical trial of treatment strategies for attention deficit hyperactivity disorder (ADHD). Archives of General Psychiatry, 56, 1073-1086.

Muscott, H. S., \& Guilford, T. (1994). Virtual reality and social skills training for students with behavioral disorders: Applications, challenges and promising practices. Education and Treatment of Children, 17, 417-434.

Pelham, W. E., \& Gnagy, E. M. (1999). Psychosocial and combined treatments for ADHD. Mental Retardation and Developmental Disabilities Research Reviews, 5, 225-236.

Rubin, K. H. Bukowski, W. M., \& Parker, J.G. (1998). Peer interactions, relationships and groups. In W. Damon (Series Ed.) \& N. Eisenberg (Vol. Ed.), Handbook of Child Psychology Vol.3: Social, emotional and personality development. (5th Ed.). New York: Wiley. 
Russomano, L. (2000). Achievement, locus of control, self concept, social problem solving training and the acquisition of prosocial skills in children (Doctoral dissertation, Seton Hall University, 2000) Dissertation Abstracts International, 61, (2A), 485 .

Sattler, J. (2002). Assessment of children: Behavioral and clinical applications. San Diego: Sattler, Inc.

Sheridan S. M. (1993) Social skills observation system. Unpublished manual. Department of Educational Psychology, University of Utah, Salt Lake City, UT.

Sheridan, S. M. (1995a). The tough kid social skills book. Longmont, CO: Sopris West.

Sheridan, S. M. (1995b). Social skills of children with ADHD. In S. Goldstein (Ed.), Understanding and managing children's behavior in the classroom. (pp. 375-396). New York: Wiley.

Sheridan, S. M. (1998). Building social skills in the classroom. In S. Goldstein and M. Goldstein (Eds.), Attention deficit hyperactivity disorder in children: A guide for practitioners. (2nd ed., pp. 592-612). New York: Wiley.

Sheridan, S. M., Dee, C.C., Morgan, J. C., McCormick, M.E., \& Walker, D. (1996). A multimethod intervention for social skills deficits in children with ADHD and their parents. School Psychology Review, 25, 57-76.

Sheridan, S. M., Hungelmann, A., \& Maughn, D. P. (1999). A contextualized framework for social skills assessment, intervention and generalization. School Psychology Review, 28, 84-103.

Sheridan, S. M., \& Walker, D. (1999). Social skills in context: Considerations for assessment, intervention, and generalization. In C.R. Reynolds \& T.B. Gutkin (Eds.), The handbook of school psychology (3rd ed., pp. 686-708). New York: Wiley.

Smokowski, P.R. (2003). Beyond role-playing: Using technology to enhance modeling and behavioral rehearsal in group practice. Journal for Specialists in Group Work, $28,9-22$.

Sugai, G., \& Lewis, T.J. (1996). Preferred and promising practices for social skills instruction. Focus on Exceptional Children, 29, 1-16.

Tawney, J. W., \& Gast, D.L. (1984). Single subject research in special education. Columbus, $\mathrm{OH}$ : Charles H. Merrill Publishing Co.

Von Brock, M. B., \& Elliott, S. N. (1987). Influence of treatment effectiveness information on the acceptability of classroom interventions. Journal of School Psychology, 25, 131-144.

Wells, K. C., Pelham, W. E., Kotkin, R. A., Hoza, B., Abikoff, H. B., Abramowitz, A., Arnold, L. E. et al. (2000). Psychosocial treatment strategies in the MTA study: Rationale, methods, and critical issues in design and implementation. Journal of Abnormal Child Psychology, 28, 483-505.

Witt, J. C., \& Elliott, S. N. (1985). Acceptability of classroom management strategies. In T.R. Kratochwill (Ed.), Advances in school psychology (Vol. 4, pp. 251-280). Hillsdale, NJ: Lawrence Erlbaum.

The action editor for the School Psychology Quarterly version of this article was Robyn Hess. 


\section{The Authors}

Kevin Fenstermacher, Ph.D., is a licensed School Psychologist employed at The Children's Center, an agency providing therapeutic treatment for behaviorally and emotionally troubled preschool children in Salt Lake City, Utah. He also serves as a Consultant/Trainer for the Utah State Department of Child and Family Services and the Utah Interagency Outreach Training Initiative. Dr. Fenstermacher received his Ph.D. in Educational Psychology from the University of Utah in 2001. His research interests include the management of early childhood social, emotional and behavioral disorders, attachment-related disorders in children, managing parenting stress and strategies for parent/child/ family therapy.

Daniel Olympia, Ph.D., is an Assistant Professor in the School Psychology Program at the University of Utah. He received a graduate degree from Minnesota State University at Moorhead and North Dakota State University. He completed his Ph.D. in Educational Psychology from the University of Utah in 1992. He has over 17 years of experience working in public schools as a school psychologist. Dr. Olympia's research interests include school-based interventions, social skills training, management of aggression, and home school collaboration. He has co-authored articles and books on homework strategies, home school collaboration, and academic and school-wide behavior support. The School Psychology Program at the University of Utah is accredited by the APA.

Susan M. Sheridan, Ph.D., is a Willa Cather Professor and Professor of Educational Psychology at the University of Nebraska at Lincoln. Her research interests include home-school partnerships, conjoint behavioral consultation, and social skills interventions. She was a Lightner Witmer Award recipient and received the Outstanding Young Alumnus Award from the University of Wisconsin-Madison, School of Education. She is the author or CO-author of several articles and books, including Conjoint Behavioral Consultation and Schools and Families: Creating Essential Connections for Learning. The School Psychology Program at the University of Nebraska-Lincoln is accredited by APA. 